Article

\title{
Treatment of Symptomatic Vitreous Opacities with Pharmacologic Vitreolysis Using a Mixure of Bromelain, Papain and Ficin Supplement
}

\author{
Masaru Takeuchi ${ }^{1}\left(\mathbb{D}\right.$, Po-Chuen Shieh ${ }^{2}$ and Chi-Ting Horng ${ }^{2,3, *}$ \\ 1 Department of Ophthalmology, National Defense Medical College, Saitama 359-8513, Japan; \\ masatake@ndmc.ac.jp \\ 2 Department of Pharmacy, Taijen University, Pintung 907, Taiwan; pochuen@tajen.edu.tw \\ 3 Department of Ophthalmology, Koahsiung Armed Forces General Hospital, Koahsiung 802, Taiwan \\ * Correspondence: h56041@gmail.com
}

Received: 3 August 2020; Accepted: 24 August 2020; Published: 26 August 2020

\begin{abstract}
Methods: Our research was scheduled in Southern Taiwan between April 2017 and December 2017. A total of 280 patients presenting 280 eyes were enrolled and received a series of ocular examinations. Each of our specially designed capsules contained $190 \mathrm{mg}$ bromelain, $95 \mathrm{mg}$ papain and $95 \mathrm{mg}$ ficin. In Experiment 1, 120 subjects were classified into Group 1 (one symptomatic vitreous opacity (SVO)) and Group 2 (multiple SVOs) which each subject taking two capsules every day. In Experiment 2, 160 eyes with SVOs were randomly divided into four groups including the placebo; low protease group (LPG) (1 capsule/day); middle protease group (MPG) (2 capsules/day); and high protease group (HPG) (3 capsules/day), respectively. Finally, we analyzed the change in SVOs and checked the numbers of SVOs during and after three months in our study. Results: In Experiment 1,80 subjects with one SVO were reduced to 24 cases $(30.0 \% ; 24 / 80), 40$ participants with multiple SVOs were decreased to 11 cases $(27.5 \% ; 11 / 40)$ three months later. In Experiment 2, the numbers of patients with SVOs in the placebo group was similar after three months. The disappeared rates of SVOs by treatment with fruit enzymes was $65.5 \%, 70.0 \%$ and $75.5 \%$ and for those taking one, two and three capsules daily as therapy, respectively. Hence, the results showed that the effects of treating SVOs in a dose-dependent manner; the higher the dose, the greater the SVO reduction. We also suggested that the mechanisms of dissolving and absorbing SVOs may be due to the proteinase and associated hydrolysis and antioxidant activities that may clear the compromised opacity and scavenge free radicals in the vitreous. In addition, there were no serious side effects or discomfort during treatment. Conclusion: We demonstrated that mixed-fruit-enzyme including bromelain, papain and ficin may excise SVOs and even eliminate intraocular hemorrhage by cleaving the collagen fibrils and cellular debris that may induce ocular floaters.
\end{abstract}

Keywords: symptomatic vitreous opacity; ocular floater; bromelain; papain; ficin; ocriplasmin

\section{Introduction}

The vitreous is a transparent and highly hydrated (98.5\% water) extracellular matrix (ECM) attached to the retina. Most vitreous collagen is Type II (60-75\%), followed by Type IX (25\%), Type V/XI $(10-25 \%)$ and Type IV $(<10 \%)$. The vitreous is primarily maintained by collagen fibrils including Types II, V/VX and IX. Few collagen Types I and III are also involved. Collagen fibrils may be organized into small bundles and interconnections between the bundles that allow an extended network and provide the vitreous strength due to the gel statute. Over time, it was found that vitreous collagens would decrease, resulting in the surface exposure of a "sticky" pattern of collagens. These conditions caused 
the collagen fibrils to aggregate and liquefy; this was accompanied by vitreous shrinkage and clumping, which made shadows on the retina. Subsequently, collagen fibrils were stabilized by intermolecular and intramolecular cross-links with hyaluronic acid (HA). In general, HA attracts water and inflates the gel. HA should compromise the chondroitin sulfate (CS) and heparan sulfate (HS), the important components of ECM [1]. HA is a major component of ECM in the vitreous. In the previous study, we postulated that the glycosidic bonds of polysaccharides should be cut and thus, the symptomatic vitreous opacity (SVO) may disappear [2]. According to the past analysis, vitreous liquefaction, flecks of protein, vitreous debris, inflammatory balls, blood particles and torn retina contributed to the SVOs. If left untreated, they could cause impairment of vision and permanent visual loss in the late stage [3].

In general, HA should survive in the intercellular ground and control the function of permeation. Therefore, HA maintains the biodegradable and biocompatible activities [4]. It was found that when vitreolysis happened, the disordered HA could be cut and split, with the shadows on the retina revealing floaters or becoming SVOs [5]. Many patients experienced floaters initially, but generally the symptoms were not troublesome for daily life. Clinics found that SVOs could be associated with floaters, intraocular blood clots and overgrowth of ECM. Patients with more than 10 SVOs or a cloud in front of vision had a high risk of developing retinal tears. The shadow of SVOs on the retina was determined by the diameter of the vitreous opacity, its distance from the retina and the overall distance between the pupillary plane and the retina. If SVOs were removed and absorbed by any method, the ocular floaters would diminish or disappear [6]. Usually the condition is benign and a temporary phenomenon. When SVOs aggregate to fuse together, they may be fixed or mobile especially after the development of posterior vitreous detachment (PVD) [7]. In SVOs, larger members of cobwebs-like shapes may indicate the occurrence of a serious condition such as vitreous hemorrhage $(\mathrm{VH})$ from diabetic retinopathy or trauma. Moreover, ocular dark floaters alone or combined with flashes of light may be the precursor to retinal detachment (RD) or VH [8].

The relationship between floaters and PVD is very close [9]. PVD is a natural change that occurs during adulthood. Several researchers focused on the etiologies of PVD associated with risk factors including age, oxidation and increased proteolytic activity [10]. The incidence of SVO is estimated as 3.1/100,000 per year and the peak incidence occurs between 45 and 65 years old of age [11]. There are various methods for treating SVOs including observation, neodymium-YAG (Nd-YAG) laser and pars plana vitrectomy (PPV). First, observation is the first and most reasonable choice for clinical treatment of ocular floaters. However, the functional effectiveness varies, and the prognosis is beyond the doctor's control [12]. Moreover, PPV was approved as the effective approach in completely clearing the SVOs within the visual axis. The subjects who experienced persistent or severe SVOs may be scheduled to undergo PPV. Equally, vitrectomy for VMT has many disadvantages, with only one-third of eyes gaining two or more lines by Snellen chart [13]. Sometimes, PPV was associated with the patients' economic burden and various postoperative complications such as endophthalmitis and glaucoma [14]. Moreover, RD would occur in $2.4 \%$ and $92 \%$ of eyes developed into cataract within three years after vitrectomy [15]. Comparing the severe side effects from various treatments leads, many patients to hesitate the invasive approach. Therefore, our purpose is to determine how to develop new, effective and safe methods for treating SVOs.

In this study, we designed a capsule containing a mixture of fruit enzymes including bromelain, papain and ficin with the ability to hydrolyze the components of SVOs and cleave the combination of collagen fibrils and HA. In our past study, we demonstrated that consumption of pineapple would decrease ocular floaters. Furthermore, we found that three proteinase enzymes, bromelain, papain and ficin, which were all extracted from the crude pineapple, cut and cleared ocular floaters and opacities (not published yet). According to the analysis, the stems and fruits of pineapples contain various proteases and collagenase, which are responsible for debridement and dissolve the overgrowth of tissues including several proteins and polysaccharides. These are the components of degraded HA [16]. Doneva et al. used the exogenous enzymes such as bromelain, papain and ficin to break down some low-weight connective tissue. For example, the proteinase from bromelain would cleave both 
myofibrillar and collagen protein [17]. In fact, various fruit enzymes have long been used to treat the human disease. However, the medical applications for ocular diseases have so far been rare. In our research, we tried to determine the effectiveness of papain, ficin and bromelain by intake and analyze their ability to degrade SVOs, which aggregated the collagen fibrils. If SVOs diminished and disappeared, our fruit enzyme therapy should be considered as a good regimen with rapid, simple and safe characteristics.

\section{Materials and Methods}

\subsection{Materials}

The three fruit enzymes were obtained commercially. The bromelain powder was obtained from Xi'an Sgneck Biologic Technology. Co., Ltd. (China), the papain powder was purchased from Shaanxi Hongda Phytochemistry. Co., Ltd. (China) and the ficin powder was from HK. Gotopharm Co., Ltd. (Taiwan). The molecular weight and isoelectric point (Mw, PI) are $(33000,9.55),(23406,8.75)$ and $(26000,9.0)$ for bromelain, papain and ficin, respectively [18-20]. A special enteric release capsule was used for all participants to prevent damaging the oral enzymes in the stomach and enhance absorption from the small intestine. The components of the slow released capsule were hydroxyl propyl methylcellulose (HPMC) and pectin. One capsule included $190 \mathrm{mg}$ bromelain, $95 \mathrm{mg}$ papain and $95 \mathrm{mg}$ ficin. According to the experimental design, 280 subjects took the capsules.

\subsection{Patient Collection Criteria}

This study followed the Declaration of Helsinki, and the ethical clearance (KAFGHIRB no. KAFGH 106-003) was received from the human research ethics committee of Koahsiung Armed Forces General Hospital. Informed consent was obtained from each participant. This approved prospective study included 280 consecutive eyes of 280 cases diagnosed as ocular SVOs in Southern Taiwan from April to December in 2017. All participants were between 20 and 60 years of age. We recorded the age, gender and the numbers of SVOs for all participants. Informed consent was obtained from volunteers and conducted in accordance with the Declaration of Helsinki. The ethical approval was from the institutional review board of Kaohsiung Armed Forces General Hospital (Kaohsiung, Taiwan, ROC; No. KAFGH-106-003). The definition of "SVOs" was ocular vitreous floaters severe enough to cause symptoms. The images could be found by a series of ocular examinations over a minimum time period of 3 months. In general, most of the patients complained about floaters and the physicians did not discover anything else in the vitreous. We first collected subjective complaints from the patients, and then collected objective findings from indirect ophthalmoscopy (Loyal Tech Group Co., Ltd.), Ultra Scan-B (Alcon., Co., Ltd.) and optical coherence tomography (OCT) (Clinico., Co., Ltd.). When the results were consistent, the victims were enrolled. Retinal images were considered the same regardless of shapes, and any numbers of SVOs greater than one was considered as multiple SVOs. Patients were excluded if the signs from examinations were not apparent when they subjectively suffered from floaters. No patients had received any ocular surgery within 6 months. Cases of posterior uveitis, posterior lymphoma and endophthalmitis were also excluded because of the complicated course. Cases of the intraocular tumors and emulsified silicone oil droplets from intravitreal injections were also excluded. However, the VH from DR, hypertensive retinopathy and trauma could be enrolled. However, the above subjects could not receive any treatment for intraocular hemorrhage.

\subsection{Experimental Design and Laboratory Examination}

Indirect ophthalmoscopy was first used to confirm the larger floaters. In Experiment 1, 120 patients were separated into 2 groups made up of those with one SVO and those with multiple SVOs. They all took 2 capsules contained fruit enzymes daily. Moreover, in Experiment 2, 160 SVOs were randomly divided into 4 groups: placebo group (40 cases), low protease group (LPG) (40 cases), middle protease group (MPG) (40 cases) and high protease group (HPG) (40 cases). Afterward, the patients took 0 , 
1, 2 and 3 capsules each day, respectively. The end-point of our study was 3 months for the whole experiment. When the image in the one SVO group disappeared to a zero image, this case was considered "successful". Moreover, if the images in the multiple SVOs group decreased to one or zero image, the subjects were considered "successful". All the subjects returned to our outpatient department and received the same ocular checkup every month. We recorded the numbers of SVOs during and after the 3-month remedy. We also evaluated the best corrected visual acuity (BCVA) of the subjects at the end of every month.

\subsection{Statistical Analysis}

All results were shown as mean \pm standard deviation (SD). To examine the differences of the continuous variable distributions between the control group and the fruit enzymes group, the paired t-test was performed for normally distributed data. All data were analyzed with the use of SAS 9.0 (SAS Inst., Cary, NC, USA).

The difference was compared by paired $t$-test in Experiment 1 . We further compared the results between placebo, LPG, MPG and HPG at baseline and during the whole 3 months by Scheffé test. Moreover, the results between the 4 groups were analyzed by Williams' test in Experiment 2. A $p$-value $<0.05$ was considered statistically significant.

\section{Results and Discussion}

\subsection{Patient Characteristics}

A total of 180 right eyes and 100 left eyes were enrolled. A total of 182 males and 98 females took part in the study and their mean age was $48 \pm 3$ years old which was compatible with most of the vitreous liquefaction happening after age 40. Additionally, no retinal damage or ocular inflammation was observed, and the 280 participants had no apparent side effects or discomfort, thus showing that the mixed-fruit enzymes are safe. The intraocular pressure, blood sugar and blood pressure of all subjects was all within normal range. The best corrected visual acuity (BCVA) was improved, but it was not statistically significant difference. Moreover, the angle of anterior chamber, lens status, cornea and zonular fibers all showed normal by slit lamp and anterior segment OCT. This could explain why the three fruit enzymes did not impact and absorb the collagen fibrils in ocular tissues except in the vitreous in our research.

\subsection{The Effect of Fruit Enzymes on the Change of Various Floaters}

In Experiment 1, 80 patients with one SVO decreased to 24 subjects $(30.0 \%)(p<0.05)$ and the rate of treatment success was $70 \%$ after three months. The 40 participants with multiple SVOs decreased to 11 patients $(27.5 \%)$ after the three-month therapy $(p<0.05)$. All 120 patients took one capsule twice daily and each capsule included $190 \mathrm{mg}$ bromelain, $95 \mathrm{mg}$ papain and $95 \mathrm{mg}$ ficin. The disappeared rate was $72.5 \%$ in the multiple-SVOs group (Table 1). The pathologic features showed improvement as shown in Figures 1-3.

Table 1. Change in various floaters before and after taking the fruit enzymes over a 3-month treatment. All 120 patients all took the capsule twice daily. The capsule of fruit enzymes included $190 \mathrm{mg}$ bromelain, $95 \mathrm{mg}$ papain and $95 \mathrm{mg}$ ficin.

\begin{tabular}{|c|c|c|c|c|}
\hline Numbers of SOVs ${ }^{1}$ & Before & 1st Month & 2nd Month & 3rd Month \\
\hline One & 80 & 78 & 68 & $24 *(30.0 \%)$ \\
\hline Multiple $^{2}$ & 40 & 37 & 30 & $11 *(27.5 \%)$ \\
\hline
\end{tabular}

${ }^{1} \mathrm{~N}=120$ eyes (in the one and multiple SVOs groups); ${ }^{2}$ In the two groups, we compared all the results between baseline and after treatment 1st month, 2nd month and 3rd month) by pair-t-test. A $p$-value less than 0.05 showed a significant difference (We make* as a symbol); 


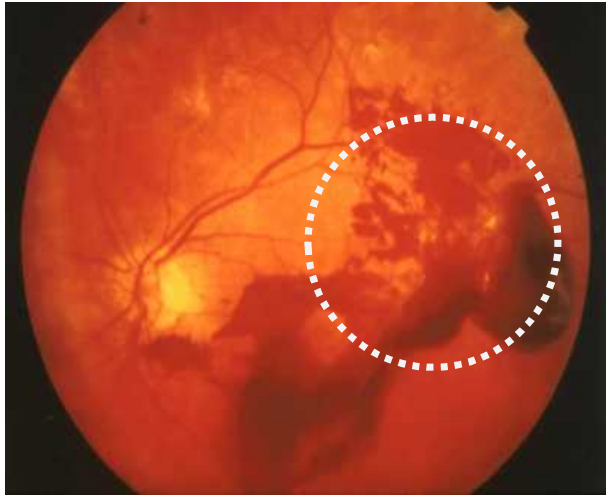

(a)

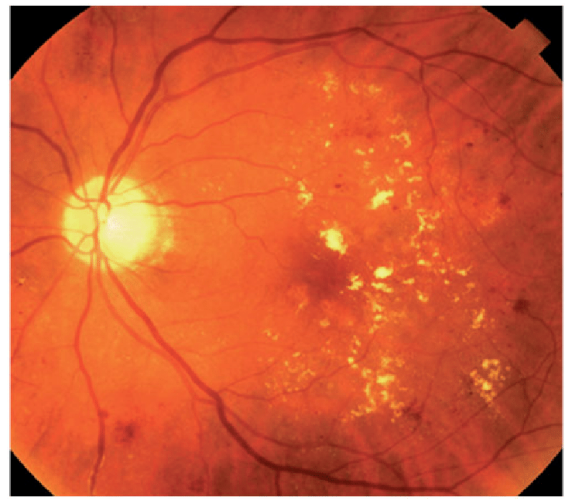

(b)

Figure 1. (a) Large numbers of dark floaters or cobwebs indicated the appearance of vitreous hemorrhage before treatment; (b) multiple symptomatic vitreous opacity gradually disappeared as perceived intraocular blood clots after 3 months of treatment.

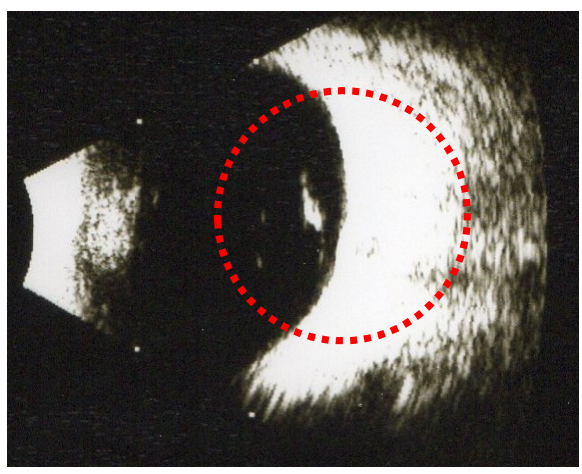

(a)

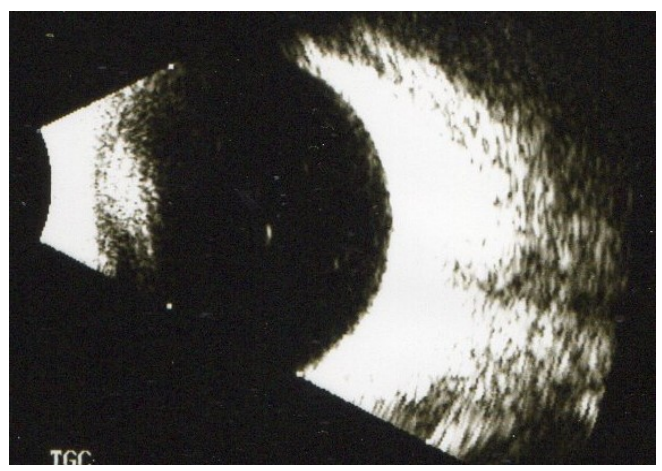

(b)

Figure 2. (a) One symptomatic vitreous opacity was found under B-scan before treatment. (b) The symptomatic vitreous opacity disappeared significantly as observed by ultrasound after 3 months of treatment with fruit collagenase supplements.

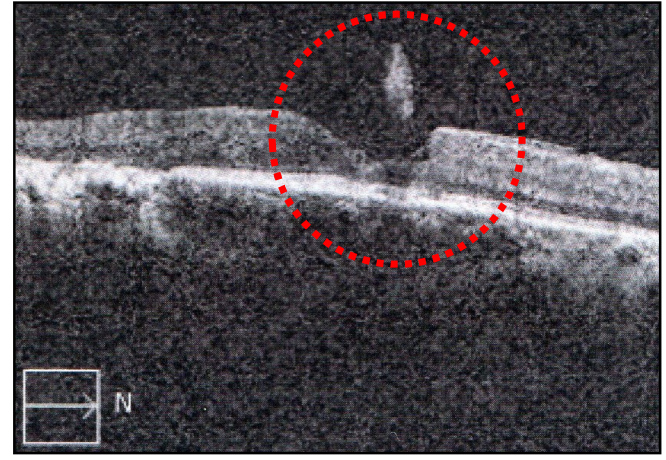

(a)

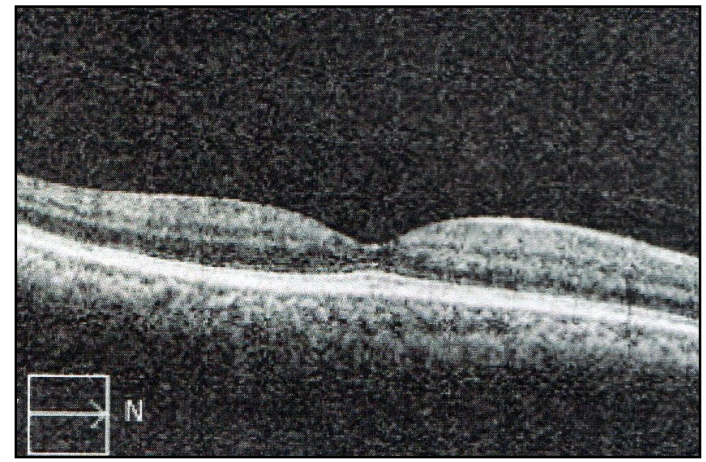

(b)

Figure 3. (a) Image of vitreous opacity in the posterior vitreous was observed by the optical coherence tomography (OCT) before treatment; (b) symptomatic image of vitreous opacity in the humor vitreous disappeared after taking three fruit enzymes supplement for three months. 


\subsection{The Effect of Fruit Enzymes at Differential Concentration on the Change of Various Floaters}

The disappeared rate was $65 \%, 70 \%$ and $75 \%$ of SVOs in the 1-, 2- and 3-capsule groups after 3 months of taking the mixed-fruit-enzyme supplements $(p<0.05)$ (Table 2). Hence, the result also showed the dose-dependent correlation between at the higher dose of enzyme intake and the higher disappeared rates. The higher doses of our capsules have a stronger hydrolysis ability for degrading SVOs. However, the ocular opacity in the placebo group did not vanish remarkably without the fruit enzymes $(p>0.05)$. During ocular examinations, we found that SVOs had absorbed in the "successful" cases. The capsules should enhance the functions of hydrolysis and lysis. Furthermore, we also found that SOVs from patients with diabetic retinopathy could be dissolved by fruit enzymes and the mechanism of disappearance of $\mathrm{VH}$ may be primarily due to the antithrombotic function of papain. Therefore, we suggested that taking a combination of bromelain, papain and ficin was good for dissolving and absorbing ocular opacities easily.

Table 2. Change in ocular floaters before and after the fruit enzymes at differential concentration over a 3-month treatment.

\begin{tabular}{ccccc}
\hline Numbers of Capsules Each Day & Before & 1st Month & 2nd Month & 3rd Month \\
\hline none & 40 & 40 & 40 & $38(95.0 \%)$ \\
1 capsule & 40 & 38 & 33 & $14^{*}(35.0 \%)$ \\
2 capsules & 40 & 35 & 32 & $12^{*}(30.0 \%)^{\#}$ \\
3 capsules & 40 & 34 & 30 & $10^{*}(25.0 \%)^{\#}$
\end{tabular}

1. Group $1(n=40$ eyes): no proteases were taken (placebo group). Group 2: $(n=40$ eyes): all volunteers took 1 capsule with mixed proteases including $190 \mathrm{mg}$ bromelain, 95 papain and 95 ficin every day. Group 3 ( $\mathrm{n}=40$ eyes); All patients took 2 capsules daily. Group $4(\mathrm{n}=40$ eyes): all patients took 3 capsules daily. 2 . At first, we compared the results at the beginning and during the whole 3 moths by Scheffe test in the four groups. Statistical significance was considered at $p<0.05$ (We make* as a symbol). 3. Moreover, we further compared the outcome at the 3rd month (Group 2, Group 3 and Group 4) with the placebo group by Williams' test. A p-value of less than 0.05 was considered to indicate a statistically significant difference (We mark \# as a symbol).

The ocular floaters may bother the daily life of the victims. For example, Vanova et al. demonstrated that the floaters could impact the quality of life with respect to vision-dependent tasks and found more than two-thirds of the patients had moderate to extreme difficulty in reading small print and even in driving at night [21]. Chronic floaters may be just as problematic for some individuals as other well-established ocular conditions that are viewed as having more impact on visual functioning, such as cataract or macular membrane. Additionally, Wagle et al. concluded that degenerative SVOs had a negative impact on patient's health-related life [22]. The cohort studied by this group on average was willing to accept a 7\% risk of blindness to eliminate SVOs, and this risk was comparable to the associated risk of treating diabetic retinopathy and age-related macular degeneration. Obviously, the safe use of the new methods for treating SVOs is important.

The reason for the sudden onsets of ocular floaters in patients were more than 40 years old and was related to PVD in $95 \%$ of cases. Therefore, in our study, the mean age of patients was $48 \pm 3$ years old, which was compatible with other documents showing that most vitreous liquefaction occurred after age 40. The common complications from PVD are retinal tears, retinal hemorrhage, optic-disc hemorrhage, RD as well as SOVs. Furthermore, severe PVD may dramatically induce retinal tear, $\mathrm{VH}$ and RD [23]. PVD itself is not a serious problem, although it leads to local interference with the passage of light and causes the symptoms referred to as floaters. In clinics, PVD is the most common cause of acute -onset floaters. It has been found that if the eyes are exposed to various factors including visible light, ultraviolet light, ionizing radiation, environmental toxins and endoplasmic reticulum stress (ER stress), the unstable reactive oxygen species (ROS) characterized by unpaired electrons would be produced [22]. Therefore, oxidative stress could result in the formation of PVD, which degrades the combination of HA and collagen fibrils. Moreover, PVD would be accompanied by a sharp increase in floaters, but after the acute phase, the symptoms may settle down, partly owing to 
adaptation. In most cases, the initial symptoms are transient as the patients learn to 'live with them'. However, some patient cases continue to have quite troublesome floaters even with good visual acuity.

The vitreous is composed of collagen fibers $(\sim 0.5 \%)$, HA $(\sim 0.5 \%)$ and water $(\sim 99 \%)$ and is characterized by the dilute dispersion of collagen fibrils interspersed with extensive arrays of HA. Taken together, HA is the predominant macromolecule that could form a meshwork and an unbranched polymer of disaccharides linked by the glycosidic bonds. Many enzyme fruits could degrade HA by cutting the glycosidic bonds and breaking down vitreous opacity. Moreover, collagens are organized into fibrils with Types I, II, III, IV, V, VI, IX and XI, which provides a solid structure. It is also known the vitreous consists of collagens, glycosaminoglycans, PGs and hydrated ECM molecules (e.g., fibrillin and opticin). With aging, there is a loss of Type IX collagen from the fibril surfaces. Moreover, loss of the Type IX collagen chondroitin sulfate chains from the fibril surfaces combined with increased surface exposure of Type II collagen results in fibrillar aggregation. Finally, the purpose of any method of vitreolysis for treating SVOs is to clear vitreous strands and opacities.

Current treatments for ocular floaters and SVOs include observation, Nd:YAG laser vitreolysis, PPV and newly developing pharmacologic vitreolysis. At first, close and regular observation by experienced ophthalmologists was indicated when the victims experiencing limited vision were relatively young or extremely old. Patients with few floaters and SVOs should receive close follow-up. The treatment success rate varies and cannot be predicted. However, most patients desire more aggressive treatments for resolution of visual symptoms and psychological problems. Nd: YAG laser, which vaporizes opacities, is attractive due to its effectiveness and ease in treating the middle or posterior floaters. The laser would be used for the lysis of fibers, rhexis of aggregates and displacement out of the visual axis. Now, it has been too widely used for severe vitreous strands and breaking larger opacities into small particles. For therapy, we always use the sufficient energy ( 3 to $4 \mathrm{~mJ}$ ) to treat opacity, as well as a sufficient number of laser pulses (150 to 200 pulses) to treat SVOs. Typically, only opacities relatively far from the retina are treated; thus, the therapy may be appropriate for only some patients. Unfortunately, the laser has the potential risks of cataracts, elevated IOP, posterior capsule defects, retinal tear or hemorrhage and RD [24]. However, the amorphous floaters in the midto posterior vitreous are difficult to visualize and treat by laser sometimes. As of 2011, PPV may be a better option for more diffuse vitreous opacities, fibril strands, VMT and FTMHs and could remove the damaged vitreous, thereby clearing the floaters in the visual axis. Although the results showed that $85 \%$ of participants were satisfied by surgery, most of the patients preferred food supplements to avoid the higher number of side effects from surgery and desired the safe and more effective conservative treatment to be developed through future research.

Except for observation, laser and PPV, the pharmacologic vitreolysis developed recently, intravitreal ocriplasmin (microplasmin) (Jetrea; Thrombogenics USA, Alcon) injection is a recombinant and truncated form of human 27 kilodalton serine protease plasmin, a non- surgical option and alternative treatment instead of PPV for VTM that induces smaller fragments of enzyme [25,26]. Furthermore, ocriplasmin is enzymatically able to degrade cleaved collagens, fibronectin, laminin, over growth tissues, extra-ECM, futile vitreous fibrils and the protein scaffold between the vitreo-retinal space. For patients with SOVs, a single intravitreal injection of $0.125 \mathrm{mg}$ should be used to treat the subjects by cutting vitreous strands and opacity. Current options showed that ocular floaters, SVOs and proliferative tissues could be dissolved by the proteolytic and collagenotic functions of ocriplasmin. Moreover, the mechanism of ocriplasmin for treating SVOs and enhance the traction release successfully and achieved an improvement of $26.5 \%$ at Day 28 [27]. Ocular floaters and SVOs are the consequence of vitreous attachment with disturbance of the retina, which would be dissolved by ocriplasmin. It was even reported that patients with SVOs who received an ocriplasmin injection had a response rate that reached about $11 \%$. In addition, dose- and time-dependent cleavage was achieved by ocriplasmin between posterior vitreous cortex and ILM. However, the adverse events included acute reduction in vision, metamorphopsia, visual field defect, ERG changes, dyschromatopsia, retinal tear or detachment, 
lens subluxation and phacodonesis. Intravitreal injection also has several complications such as endophthalmitis, glaucoma, cataract and even RD [25].

During aging, the vitreous progressively liquefies and pockets of liquid form in the gel. The first liquefaction has been observed in individuals at 4 year of ages when $20 \%$ of the vitreous is liquid; after age 40 liquefaction increases so that by age 80 , more than half of the vitreous is liquid which is called "synchysis" [26]. This age-related redistribution of the fibrillar components of the vitreous leaves the spaces between the collagen cables filled with liquid. The process has been termed "synchysis senile". The collagen fibrils of the core aggregate into thick cables, instead of the random orientation of fine fibrils in the gel network earlier in life. Liquefaction is caused by the aggregation of collagen fibrils which induces redistribution of the fibrils, with the aggregates becoming more highly concentrated in some of the gel, while other parts of the vitreous developed a lack of fibrils and are converted into liquid compartments. Over the next 1 to 3 months, the vitreous gel further condenses, and the sides of the gel also separate from the retina until the PVD is complete [27]. Hence, the shadows cast on the retina could reveal ocular floaters. The collagen filaments aggregation and condensation resulted in the formation of larger fibrils, which float in lacunas of liquefied vitreous giving the patients the perception of floaters. The speed at which these vitreous changes happen depends on age, environmental factors, exposure to sunlight or blue light, oxidative stress and HA-collagen interaction [28]. If PVD gently progresses, the symptoms are mild. However, if the forces of separation are strong, PVD could tear the retina or retinal blood vessels. Moreover, in PVD, the vitreous shrinks and leads to ocular floaters. It was found that in $14 \%$ of cases, traction forces from the vitreous jelly sometimes caused retinal tears [29]. If left untreated, the tears may induce to break and allow fluid to enter into the subretinal space which results in RD. Therefore, we developed a new method of pharmacologic vitreolysis using the fruit enzymes bromelain, papain and ficin. We suggested that there are at least three mechanisms for treating SVOs and floaters in our new method. First, metalloproteinase (MMPs) plays an important role in mediated message and proteolysis. Second, these three fruit enzymes have the ability to dissolve and cleave the abnormal ECM and vitreous opacities. Finally, these enzymes also support the antioxidant protection in oxidase stress from vitreous changes. In human body, the MMPs degraded the components of the complex ECM. It was also found that MMP-2 would cleave collagen Types I, II and III, while MMP-9 would cut collagen Types I, III and IV. Therefore, MMPs could clear SVOs in patients and decrease ocular floaters [30,31]. The endogenous MMPs are even beneficial for pharmacologic vitreolysis and some vitreo-retinal diseases such as VMT and macular holes. Recently, it was revealed that different levels of MMP-2 and MMP-9 were found in ficin, bromelain and papain. Furthermore, endothelial progenitor cells also play an important role mediated by MMPs for matrix absorbing and remodeling. The MMPs, which were found in the vitreous of patients in the proliferative phase, could degrade the ECM, growth factors and compromised collagens. Furthermore, papain is found to have MMP-2 and MMP-9 abilities. Ficin was demonstrated to cut collagen I, II, III and IV from MMP-2 and MMP-9 biochemical functions. In addition, bromelain also has MMP-2 [32]. In other words, the mixture of fruit enzymes was considerable enough to have proteolytic function. In the past, vitreous floaters from blood clots and other opacities would be removed by laser vitreolysis and PPV. Now, however, taking the capsules of mixed-fruit-enzyme significantly decreased the persistence of floaters after the 3-month period. Hence, we proposed that oral fruit proteinase for dissolving and hydrolysis should be beneficial instead for laser and PPV. We analyzed the ability of bromelain, papain and ficin and revealed the hydrolytic function from fruit enzymes by MMPs.

There are many uses for pineapple and its derived ingredients. For example, bromelain is one of the most popular fruit enzymes that is extracted from the pineapple stem and fruit. Recently, bromelain was introduced and originally applied to any protease from the plant family Bromeliaceae [16,33]. The cysteine proteases, including papain, bromelain and ficin, are the most abundant in Bromeliaceae and belong to a free sulfhydryl group of a cysteine amino acid side chain that is required for function. It is reported that the medical advantages of bromelain may be due to its proteolytic and hydrolytic activities. Bromelain has hydrolytic, antifibrinolytic, anti-inflammatory and antithrombotic properties. 
The stem is the most common source because of its usable quantities. However, care should be taken because of its side effects of allergy and hyperglycemia.

Papain belongs to a nonspecific cysteine proteinase characterized by broad substrate specificity; its hydrolysis makes papain an enzymatic supplement [34]. Papain is a proteolytic enzyme extracted from the latex of the raw fruit of the papaya plant that possesses hydrolytic enzymes that may enhance breaking down larger proteins into smaller fragments called peptides and amino acids. This is why papain is a common ingredient in meat tenderizers [35]. The mechanism of papain breaking peptide bonds involves the catalytic diisopropyl azodicarboxylate with a deprotonated cysteine that breaks the pieces of tissue into proteins, collagen and fibrils. Furthermore, papain can clear the fibrillary collagen II. Papain belongs to a type of the cysteine proteinase that cleaves propeptides. However, the collagenase activity of bromelain was twice higher than papain activity in the laboratory. In several studies, it has been found that papain has cathepsin K, which could cut Types I and II collagen and adjust the degradation. Furthermore, cathepsin $\mathrm{L}$ is also similar to papain-like collagenase and would efficiently cut Type I primarily and other collagens. Therefore, papain has the functions of cathepsin collagenases and degrades various types of collagens and ECM components [36]. Additionally, papain plays an important role in many biologic functions such as protein cleaving, cell dissociation and even necrotic tissue treatment. Papain has good efficacy in controlling inflammation, so it has often been used to treat arthritis and bronchitis. The preliminary studies of 11 fractions of low-molecular-weight collagen peptides obtained through enzymatic hydrolysis were investigated. It was then suggested papain may be used to dissolve the vitreous opacity and get rid of ocular floaters. Combined with papain, bromelain treatment has higher collagen solubility. In clinics, doctors may use papain to reduce pain and inflammation from trauma from surgery, aid digestion, heal wounds, relieve herpes zoster symptoms, kill parasitic worms and insects, control psoriasis and hypertension and lower blood sugar [37]. However, it has been found that papain increases bleeding tendency and decreases platelet aggregation which could be beneficial for preventing strokes. In our study, we also found that ocular floaters from proliferative diabetic retinopathy with $\mathrm{VH}$ could disappear by the antithrombotic ability of papain. In addition, papain could boost the potency of the anticoagulants such as aspirin and warfarin. Very few papain consumers develop rashes, unapparent breathing constriction and mild chest pain. Therefore, papain intake is relatively safe.

Finally, ficin is a fruit enzyme that is derived from a latex substance from the trunk of Ficus carica. This proteinase, ficin, belongs to the serine protease family and the mechanism of vitreolysis is like the function of ocriplasmin [38]. Moreover, enzymatic activity of ficin depends on the sulfhydryl group of a cysteine residue at the active sites. It also belongs to a family of cysteine endopeptidases that includes ficin, papain, bromelain, calpain, caspases and cathepsin B. In medical procedures, ficin is used in the production of stitching material (sutures), in the preparation of animal arteries for implantation in people and in blood typing. Ficin breaks down proteins and kills intestinal worms. Moreover, ficin is also used in making cheese and sausage casings and chill-proofing beer. Moreover, it also serves as a preserver, lipolytic agent and mild coagulant. In addition, ficin is sometime included in meat tenderizers in combination with papain and bromelain. We also found ficin has the antioxidation, anti-inflammation, antibacterial activities and whitening effects after intake. Moreover, people can take ficin for digestion problems and to get rid of intestinal worms. Ficin may inhibit mRNA and protein expression levels and be used for proteolytic degradation and solubility of elastin, collagen and various fibers $[39,40]$. Furthermore, ficin and bromelain also appears to be equally effective on collagen, while papain is less effective. Recently, ficin was demonstrated to cleave collagen I, II, III and IV. In the slit lamp examination and electron microscopy, we found that insoluble fibrils could be depolymerized to a soluble form by several proteolytic enzymes such as pepsin and ficin. Furthermore, swollen fibrils could be found after digestion by hydrolytic enzymes. We suggested that ficin may be beneficial for cutting collagen fibrils and intermolecular cross-link, thus causing SVOs and floaters to disappear.

Previously, we reported that vitreous floaters could be significantly absorbed after a 3-month pineapple supplement [41]. After further biochemical analysis, we extracted at least 3 main fruit 
enzymes from pineapple including bromelain, papain and ficin. The ratio of the proteinase was 2:1:1, respectively. We have now recently shown that one capsule including $190 \mathrm{mg}$, papain $95 \mathrm{mg}$ and $95 \mathrm{mg}$ ficin for adults ( $>20$ years old) may offer the maximal pharmacologic effects (not published yet). There are many uses for our three fruit enzymes, which are close to the serine proteinases. In an effort to ease the burden of patients who are bothered by SVOs and floaters, the method of using oral proteolytic enzymes from fruits appears safe and avoids the risks of intraocular surgery including YAG laser and vitrectomy. VH may also be absorbed by the fibrinolysis from the papain. Therefore, patients with ocular floaters, PVD and even proliferative tissues may be treated, and their condition improved by the fruit enzyme intake. Hence, in our therapeutic option, this may open new insights into the treatment of human floaters, PVD and associated vitreous fibrils. Our studies revealed that the special mixed-fruit-enzyme supplement taken daily can offer an inexpensive alternative to current therapies for ocular floaters.

\section{Conclusions}

In this study, we demonstrated that the combination of papain, bromelain and ficin significantly dissolved and absorbed the vitreous opacities. Moreover, free radicals could scavenge by some fruit enzymes. Furthermore, we found the regular fruit enzymes intake resulted in a dramatic disappeared rates of SVOs with fewer side effects. The mixture of fruit enzymes may have potential application such as the complex pharmacokinetics for patients with SVOs and ocular floaters. Moreover, the mechanisms of pharmacologic vitreolysis such as hydrolysis and antioxidant function were also presented.

Author Contributions: Conceptualization, M.T. and C.-T.H.; investigation, P.-C.S.; resources, C.-T.H.; data curation, M.T. and P.-C.S.; formal analysis, M.T. and P.-C.S.; writing-original draft preparation, C.-T.H.; writing-review and editing, C.-T.H. All authors have read and agreed to the published version of the manuscript.

Funding: This research received no external funding.

Conflicts of Interest: The authors declare no conflict of interest.

\section{References}

1. Yamada, S.; Sugahara, K.; Özbek, S. Evolution of glycosaminoglycans. Commun. Integr. Biol. 2011, 4, 150-158. [CrossRef]

2. Jackson, T.L.; Nicod, E.; Simpson, A.; Angelis, A.; Grimaccia, F.; Kanavos, P. Symptomatic Vitreomacular Adhesion. Retina 2013, 33, 1503-1511. [CrossRef]

3. Milston, R.; Madigan, M.C.; Sebag, J. Vitreous floaters: Etilogy, diagnosis, and management. Surv. Ophthalmol. 2016, 61, 211-227. [CrossRef]

4. Turon, P.; Del Valle, L.J.; Aleman, C.; Puiggalí, J. Biodegradable and Biocompatible Systems Based on Hydroxyapatite Nanoparticles. Appl. Sci. 2017, 7, 60. [CrossRef]

5. Lumi, X.; Hawlina, M.; Glavač, D.; Facsko, A.; Moe, M.C.; Kaarniranta, K.; Petrovski, G. Ageing of the vitreous: From acute onset floaters and flashes to retinal detachment. Ageing Res. Rev. 2015, 21, 71-77. [CrossRef]

6. Colucciello, M.; Sebag, J.; Koch, F. Controversies in care-Vitrectomy for floaters. Retin. Phys. 2014, 11, 14-17.

7. Morita, H.; Funata, M.; Tokoro, T. A clinical study of the development of posterior vitreous detachment in high myopia. Retina 1995, 15, 117-124. [CrossRef]

8. Overdam, K.; Bettink-Remeijer, M.W.; Klaver, C.C.W.; Mulder, P.G.; Moll, A.C.; Van Meurs, J.C. Symptoms and Findings Predictive for the Development of New Retinal Breaks. Arch. Ophthalmol. 2005, 123, 479-484. [CrossRef]

9. Ponsioen, T.L.; Van Luyn, M.J.A.; Van Der Worp, R.; Van Meurs, J.C.; Hooymans, J.; Los, L.I. Collagen Distribution in the Human Vitreoretinal Interface. Investig. Opthalmol. Vis. Sci. 2008, 49, 4089-4095. [CrossRef]

10. Akiba, J.; Ueno, N.; Chakrabarti, B. Mechanisms of photo-induced vitreous liquefaction. Curr. Eye Res. 1994, 13, 505-512. [CrossRef] 
11. Mason, J.O., III; Neimkin, M.G.; Mason, J.O., IV; Friedman, D.A.; Feist, R.M.; Thomley, M.L.; Albert, M.A. Safety, efficacy, and quality of life following sutureless vitrevtomy for symptomatic vitreous floater. Retina 2014, 34, 1055-1061. [CrossRef]

12. Vandorselaer, T.; Van De Velde, F.; Tassignon, M.J. Eligibility criteria for Nd-YAG laser treatment of highly symptomatic vitreous floaters. Bull. Soc. Belg. D'ophtalmol. 2001, 280, 15-22.

13. Stoffelns, B.M.; Vetter, J.; Keicher, A.; Mirshahi, A. Pars plana vitrectomy for visually disturbing vitreous floaters in pseudophakic eyes. Klinische Monatsblätter für Augenheilkunde 2011, 228, 293-297. [CrossRef]

14. Shi, X.-Y.; Zhao, H.-S.; Wei, W.-B. Analysis of post-operative endophthalmitis after pars plana vitrectomy: A 10-year experience at a single center. Chin. Med. J. 2013, 126, 2890-2893.

15. Goh, Y.W.; Ehrlich, R.; Stewart, J.; Polkinghorne, P. The Incidence of Retinal Breaks in the Presenting and Fellow Eyes in Patients With Acute Symptomatic Posterior Vitreous Detachment and Their Associated Risk Factors. Asia Pac. J. Ophthalmol. 2015, 4, 5-8. [CrossRef]

16. Arshad, Z.I.M.; Amid, A.; Yusof, F.; Jaswir, I.; Ahmad, K.; Show, P.L. Bromelain: An overview of industrial application and purification strategies. Appl. Microbiol. Biotechnol. 2014, 98, 7283-7297. [CrossRef]

17. Doneva, M.; Nacheva, I.; Dyankova, S.; Metodieva, P.; Miteva, D. Application of plant proteolytic enzymes for tenderization of rabbit meat. Biotechnol. Anim. Husb. 2018, 34, 229-238. [CrossRef]

18. Hafid, K.; John, J.; Sayah, T.M.; Domínguez, R.; Becila, S.; Lamri, M.; Dib, A.L.; Lorenzo, J.M.; Gagaoua, M. One-step recovery of latex papain from Carica papaya using three phase partitioning and its use as milk-clotting and meat-tenderizing agent. Int. J. Biol. Macromol. 2020, 146, 798-810. [CrossRef]

19. Gagaoua, M.; Boucherba, N.; Bouanane-Darenfed, A.; Ziane, F.; Nait-Rabah, S.; Hafid, K.; Boudechicha, H.R. Three-phase partitioning as an efficient method for the purification and recovery of ficin from Mediterranean fig (Ficus carica L.) latex. Sep. Purif. Technol. 2014, 132, 461-467. [CrossRef]

20. Morellon-Sterling, R.; El-Siar, H.; Tavano, O.L.; Berenguer-Murcia, Á.; Fernández-Lafuente, R. Ficin: A protease extract with relevance in biotechnology and biocatalysis. [published online ahead of print, 20 June 2020]. Int. J. Biol. Macromol. 2020, 162, 394-404. [CrossRef]

21. Ivanova, T.; Jalil, A.; Antoniou, Y.; Bishop, P.N.; Vallejo-Garcia, J.L.; Patton, N. Vitrectomy for primary symptomatic opacities: An evidence-bsed review. Eye 2016, 30, 645-655. [CrossRef]

22. Wagle, A.M.; Lim, W.-Y.; Yap, T.-P.; Neelam, K.; Eong, K.-G.A. Utility Values Associated With Vitreous Floaters. Am. J. Ophthalmol. 2011, 152, 60-65. [CrossRef]

23. Saglar, E.; Ünlü, S.; Babalioglu, I.; Gokce, S.C.; Mergen, H. Assessment of ER Stress and Autophagy Induced by Ionizing Radiation in Both Radiotherapy Patients and Ex Vivo Irradiated Samples. J. Biochem. Mol. Toxicol. 2014, 28, 413-417. [CrossRef]

24. Hahn, P.; Schneider, E.W.; Tabandeh, H.; Wong, R.W.; Emerson, G.G. American Society of Retina Specialists Research and Safety in Therapeutics (ASRS ReST) Committee Reported Complications Following Laser Vitreolysis. JAMA Ophthalmol. 2017, 135, 973-976. [CrossRef]

25. Bennison, C.; Stephens, S.J.; Lescrauwaet, B.; Van Hout, B.; Jackson, T.L. Cost-effectiveness of ocriplasmin for the treatment of vitreomacular traction and macular hole. J. Mark. Access Health Policy 2016, 4, 215. [CrossRef]

26. Koss, M.J.; Falabella, P.; Pfister, M.; Niemeyer, M.; Kashani, A.H.; Humayun, M.S.; Maia, M.; Stefanini, F.R. Profile of ocriplasmin and its potential in the treatment of vitreomacular adhesion. Clin. Ophthalmol. 2014, 8, 847-856. [CrossRef]

27. Gishti, O.; Nieuwenhof, R.V.D.; Verhoekx, J.S.N.; Overdam, K. Symptoms related to posterior vitreous detachment and the risk of developing retinal tears: A systematic review. Acta Ophthalmol. 2019, 97, 347-352. [CrossRef]

28. Sharma, M.C.; Regillo, C.D.; Shuler, M.F.; Borrillo, J.; Benson, W.E. Determination of the incidence and clinical characteristics of subsequent retinal tears following treatment of the acute posterior vitreous detachment-related initial retinal tears. Am. J. Ophthalmol. 2004, 138, 280-284. [CrossRef]

29. Nita, M.; Grzybowski, A. The Role of the Reactive Oxygen Species and Oxidative Stress in the Pathomechanism of the Age-Related Ocular Diseases and Other Pathologies of the Anterior and Posterior Eye Segments in Adults. Oxid. Med. Cell. Longev. 2016, 2016, 3164734. [CrossRef]

30. Bottós, J.M.; Elizalde, J.; Rodrigues, E.B.; Maia, M. Current concepts in vitreomacular traction syndrome. Curr. Opin. Ophthalmol. 2012, 23, 195-201. [CrossRef]

31. Page-McCaw, A.; Ewald, A.J.; Werb, Z. Matrix metalloproteinases and the regulation of tissue remodelling. Nat. Rev. Mol. Cell Biol. 2007, 8, 221-233. [CrossRef] [PubMed] 
32. Shekhter, A.B.; Balakireva, A.V.; Kuznetsova, N.V.; Vukolova, M.N.; Litvitsky, P.F.; Zamyatnin, A.A., Jr. Collagenolytic Enzymes and their Applications in Biomedicine. Curr. Med. Chem. 2019, 26, 487-505. [CrossRef] [PubMed]

33. Hale, L.P.; Greer, P.K.; Trinh, C.T.; James, C.L. Proteinase activity and stability of natural bromelain preparations. Int. Immunopharmacol. 2005, 5, 783-793. [CrossRef] [PubMed]

34. Mótyán, J.; Toth, F.; Tőzsér, J. Research Applications of Proteolytic Enzymes in Molecular Biology. Biomolecules 2013, 3, 923-942. [CrossRef]

35. Rao, M.B.; Tanksale, A.M.; Ghatge, M.S.; Deshpande, V.V. Molecular and Biotechnological Aspects of Microbial Proteases. Microbiol. Mol. Biol. Rev. 1998, 62, 597-635. [CrossRef] [PubMed]

36. Korenč, M.; Lenarčič, B.; Novinec, M. Human cathepsin L, a papain-like collagenase without proline specificity. FEBS J. 2015, 282, 4328-4340. [CrossRef]

37. Novinec, M.; Lenarčič, B. Papain-like peptidases: Structure, function, and evolution. Biomol. Concepts 2013, 4, 287-308. [CrossRef]

38. Zare, H.; Moosavi-Movahedi, A.A.; Salami, M.; Sheibani, N.; Khajeh, K.; Habibi-Rezaei, M. Autolysis control and structural changes of purified ficin from Iranian fig latex with synthetic inhibitors. Int. J. Biol. Macromol. 2016, 84, 464-471. [CrossRef]

39. Cho, U.M.; Choi, D.H.; Yoo, D.S.; Park, S.J.; Hwang, H.S. Inhibitory Effect of Ficin Derived from Fig Latex on Inflammation and Melanin Production in Skin Cells. Biotechnol. Bioprocess Eng. 2019, 24, 288-297. [CrossRef]

40. Cho, D.-Y.; Jo, K.; Cho, S.Y.; Kim, J.M.; Lim, K.; Suh, H.; Oh, S. Antioxidant Effect and Functional Properties of Hydrolysates Derived from Egg-White Protein. Food Sci. Anim. Resour. 2014, 34, 362-371. [CrossRef]

41. Horng, C.T.; Chen, F.A.; Kuo, D.H.; Chen, L.C.; Yeh, S.S.; Shieh, P. Pharmacologic vitreolysis of vitreous floaters by 3-month pineapple supplement in Taiwan-A pilot study. J. Am. Sci. 2019, 15, 17-30.

(C) 2020 by the authors. Licensee MDPI, Basel, Switzerland. This article is an open access article distributed under the terms and conditions of the Creative Commons Attribution (CC BY) license (http://creativecommons.org/licenses/by/4.0/). 